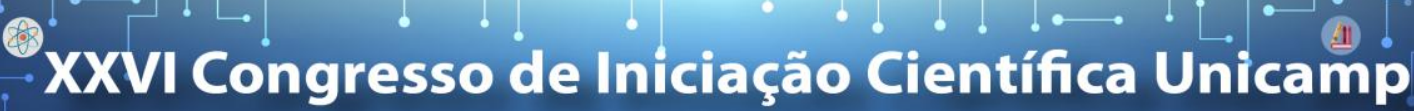

\section{Pressão de preconsolidação de um Latossolo sob controle de tráfego em área de cana-de- açúcar}

\section{Naiade de Paula Ribeiro; Diego Alexander Aguilera Esteban; Zigomar Menezes de Souza; Ingrid Nehmi de Oliveira; Elizeu de Souza Lima; Lenon Henrique Lovera}

\section{Resumo}

O sistema de produção da cana-de-açúcar promove o tráfego intenso, gerando a compactação do solo. Portanto, o objetivo deste trabalho foi estudar as alterações físicas do solo por meio do ensaio de compressibilidade da cultura da cana-de-açúcar cultivada em áreas com e sem controle de tráfego e plantada com espaçamento simples e duplo combinado. O experimento foi realizado no município de Nova Europa-SP. A capacidade de suporte de carga do solo foi avaliada na linha do rodado (LR) na camada de 0,00-0,10 m e 0,20-0,30 m. A capacidade de suporte de carga do solo foi alterada em função dos sistemas de manejo. Na linha do rodado, os sistemas de manejo com controle de tráfego agrícola, independente do teor de água no solo, apresentaram valores maiores de pressão de preconsolidação.

Palavras-chave: Piloto automático, compactação do solo, pressão de pré-consolidação.

\section{Introdução}

A cana-de-açúcar é uma importante cultura no panorama brasileiro, mas ao longo dos anos houve um intenso uso de maquinário em suas áreas, causando compactação. O controle do tráfego de máquinas com o uso do piloto automático, em área de cana-de-açúcar colhida mecanicamente, tanto para o espaçamento simples como para o espaçamento duplo combinado, reduz a compactação do solo na região da soqueira quando comparada a uma área sem controle e plantada com espaçamento simples.

Assim, o objetivo deste trabalho foi estudar as alterações físicas do solo por meio do ensaio de compressibilidade e o desenvolvimento do sistema radicular da cultura da cana-de-açúcar cultivada em áreas com e sem controle de tráfego e plantada com espaçamento simples e duplo combinado.

\section{Resultados e Discussão}

A região de friabilidade do solo (Figura 1), definida como o intervalo do teor de água entre o limite de contração e de plasticidade, apresentou-se com valor mínimo de $0,14 \mathrm{~kg} \mathrm{~kg}^{-1}$ e máximo de $0,24 \mathrm{~kg} \mathrm{~kg}^{-1}$ e, após a colheita mecanizada da cana-de-açúcar o teor de água do solo manteve-se na faixa de 0,15 a $0,20 \mathrm{~kg} \mathrm{~kg}^{-1}$, reiterando, que as operações agrícolas foram realizadas não atendendo o estado friável do solo.

Figura 1. Limites e regiões de consistência do Latossolo Vermelho distrófico nas camadas de 0,00-0,10 e 0,20-0,30 m, localizado na Usina Santa Fé no município de Nova Europa-SP, Brasil. $\mathrm{LL}=$ limite de liquidez; $\mathrm{LPL}=$ limite de plasticidade; $\mathrm{LC}=$ limite de contração.

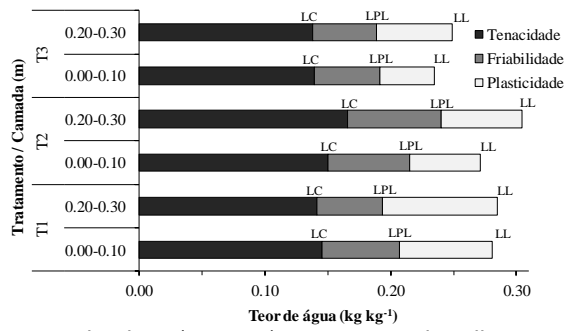

$\mathrm{T} 1$ = espaçamento simples $(1,50 \mathrm{~m})$ sem uso de piloto automático; T2 espaçamento simples $(1,50 \mathrm{~m})$ com uso de piloto automático; e T3 = espaçamento duplo combinado $(1,50 \times 0,90 \mathrm{~m})$ com uso de piloto automático.
Verifica-se que o T3 obteve CSCS maiores do que os outros tratamentos na LR, mostrando maior compactação em relação aos outros tratamentos. Este é um efeito do tráfego controlado em que a compactação ocorre apenas na LR.

As operações mecanizadas podem resultar na compactação do solo com efeitos negativos na qualidade física do solo assim, o conhecimento prévio desses efeitos deve ser um guia para medidas preventivas e minimizar danos, ajustando as condições de operação, uma vez que não há outro mecanismo que possa melhorar as produções de colheita de forma otimizada como a mecanização.

Figura 2. Modelos de capacidade de suporte de carga do solo em função do teor de água no solo com sistemas de manejo com controle de tráfego na linha do rodado (LR) após terceira colheita da cana-de-açúcar.
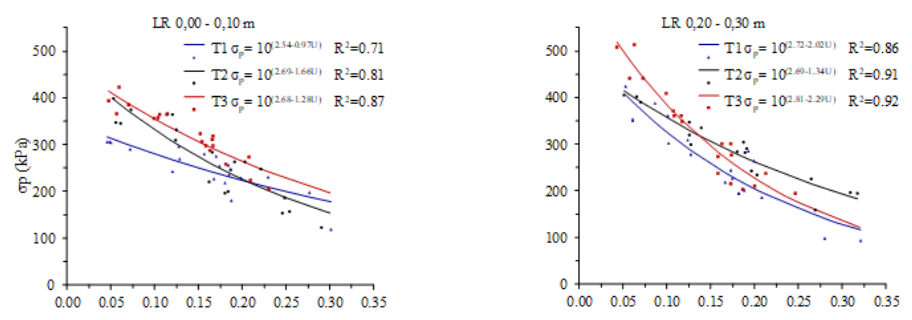

\section{Conclusões}

Menores valores de índice de compressão obtidos na linha do rodado nos sistemas com controle de tráfego indicaram menor suscetibilidade a sofrer compactação adicional, proporcionando condições mais firmes para o rodado das máquinas.

O controle de tráfego agrícola na colheita mecanizada da cana-de-açúcar aumentou a capacidade de suporte de carga na linha do rodado em relação ao canteiro, indicando que o manejo do canavial com esse sistema preserva a qualidade física do solo na região da soqueira.

\section{Agradecimentos}

Os autores agradecem a FAPESP (Projeto 2016/14751-6) pela bolsa de mestrado do acadêmico Diego Esteban e a Usina Santa Fé pela área cedida. 